\title{
Social cues influence growth and sexual maturation of the male musk shrew (Suncus murinus)*
}

\author{
E. F. Rissman, S. E. Taymans and N. L. Wayne \\ Departments of Psychology and Biology, University of Virginia, Charlottesville, VA 22901, USA
}

\begin{abstract}
Summary. Musk shrews were maintained from weaning (20 days of age) for 20 or 40 days in one of several social conditions. In Exp. 1, young males housed with adult females gained more weight and had heavier sex accessory organs than did young males housed with an adult male or reared alone. In Exp. 2 this same pattern of accelerated growth and sexual maturation was found when males were reared directly with an adult female or in a split cage where a wire barrier served to separate the male and his adult female cagemate. In Exp. 3, males were reared in cages containing clean or soiled bedding: soiled bedding was taken once every 5 days from the cage of an adult male, or a female. Under these conditions differences in the weights of reproductive tissues showed minimal variation with housing condition after 20 days of treatment. At that time males reared in soiled bedding taken from the cage of an adult female had accelerated development compared with control males. In Exp. 4, males were housed alone or in a split cage with an adult female which was separated by a wire mesh or a solid, opaque barrier. Males separated by a solid barrier from their female cagemates for 40 days had reproductive tissue weights equivalent to those measured in males reared alone. Taken together these results suggest that the presence of an adult female has dramatic effects on body growth and development of reproductive target tissues in young male musk shrews. Male-female social interactions could play an important role in the timing of puberty in this opportunistically breeding tropical mammal.
\end{abstract}

Key'words: puberty; musk shrew; reproduction; androgens; pheromones; insectivore

\section{Introduction}

The vast majority of mammal species reside in the tropics, and it is likely that modern mammals evolved there, yet little is known about the basic reproductive biology of tropical mammals. Tropical mammals often reproduce aseasonally, perhaps in response to sporadic variation in rainfall, food and/or mate availability (Sadleir, 1969; Bronson, 1985). Little information is available on the use of environmental cues in the co-ordination of pubertal or adult reproductive activity in tropical mammals.

Many mammals that reside in the temperate zone use photoperiod as the major predictive cue for the timing of the limited breeding season (Zucker et al., 1980; Bronson \& Rissman, 1986). While several tropical species show reproductive responses to photoperiod, these effects are usually small compared with the more pronounced effects of photoperiodic manipulations on the reproductive status of temperate zone mammals (Petter-Rousseaux, 1970; Van Horn, 1975; Rissman et al., 1987). Since the degree of yearly environmental fluctuations in the tropics is small, it seems likely

\footnotetext{
*Reprint requests to: Dr N. L. Wayne, Department of Biology, Gilmer Hall, University of Virginia, Charlottesville, VA 22901 , USA.
} 
that mammals in such areas will respond to subtle changes in local conditions to time their reproductive efforts. One universally important local factor that may influence reproductive efforts is mate availability. Social conditions are known to play a role in the timing of puberty in a variety of mammals (Bediz \& Whitsett, 1979; Bronson, 1979; Vandenbergh, 1983; Rissman et al., 1984). However, the influence of social cues on reproduction in tropical mammals has received little research attention (Schilling \& Perret, 1987).

Musk shrews (Suncus murinus) are widely distributed throughout the tropical Pacific and Asia. They are present in urban and rural environs and breed throughout the year (Harrison, 1955; Peterson, 1956; Barbehenn, 1962; Morita, 1964; Louch et al., 1966). Local variation in the numbers of adults in breeding condition have been noted, as well as trends for more sexually mature individuals present during certain portions of the year. However, the particular season of peak numbers of pregnancies in females and testicular sperm numbers in males varies with the location of the study population. For example, in Malaya peak reproduction is seen in the fall (Harrison, 1955) while in West Bengal, India and southern Japan the peak is in the spring (Morita, 1964; Louch et al., 1966). Moreover, compared with differences between the breeding and non-breeding seasons in northern temperate zone mammals, these small changes in pregnancy rates and sperm numbers during the course of the year in this semi-tropical shrew are very slight.

We have undertaken a series of studies to investigate systematically the roles of several environmental cues on reproductive development in the male musk shrew. The object of the present experiments was to determine whether social conditions could regulate the sexual development of this tropical insectivore.

\section{Materials and Methods}

Animals. The musk shrews used in these experiments were born and raised in our colony at the University of Virginia. The original stock were generously provided by $\mathrm{Dr}$ G. L. Dryden in 1985 . They were descended from animals trapped in the early 1960s on the island of Guam at a latitude of $13^{\circ} \mathrm{N}$. The animal rooms were maintained on a $14 \mathrm{~h} \mathrm{light:10} \mathrm{h}$ darkness photoperiod (lights on at 07:00 h EST) at a temperature of $23 \pm 1^{\circ} \mathrm{C}$. Food (a mixture of Purina cat chow and mink chow from Milk Speciality, New Holstein, WI, USA) and water were provided ad libitum.

General methods. At 20 days of age (weaning) males were assigned to housing conditions. At weaning and once every 10 days thereafter body weights were recorded. Each experiment (except for Exp. 4) was essentially conducted twice. In one run, males were maintained for 20 days after weaning until they reached 40 days of age. In the other run they were maintained until 60 days of age. When males reached the designated age they were killed. In Exps 2, 3 and 4 , blood was collected via cardiac puncture, under halothane (2-bromo-2-chloro-1,1,1-trifluorethane; Halocarbon Labs Inc., Hackensack, NJ, USA) anaesthesia, between 08:00 and 12:00 h. It was centrifuged and the plasma frozen (at $-20^{\circ} \mathrm{C}$ ) for subsequent hormone measurements. Following blood collection, animals were rapidly killed by cervical dislocation. Reproductive organs were removed, cleaned of excess fat and weighed. Weights of one testis, one ampulla, the seminal vesicle/prostate complex and one flank pad were recorded. Sperm numbers were calculated from one testis in Exps 1-3 (Kirton et al., 1967).

Androgen assay. Two $100 \mu \mathrm{l}$ aliquants of each plasma sample were extracted with $2 \mathrm{ml}$ fresh ether. The ether fraction was rinsed, dried and measured for testosterone by radioimmunoassay. The antiserum (generously provided by Dr G. D. Niswender) cross-reacts with $5 \alpha$-dihydrotestosterone $(69 \%), 3 \alpha$-androstanediol $(14 \%)$ and $3 \beta$ androstanediol (22\%; Gay \& Kerlan, 1978). Since the assay is not specific for testosterone, the steroid measured is referred to as androgen. The assay was validated for use with musk shrew plasma by testing for parellelism and by determining whether exogenous testosterone was measured accurately when added to musk shrew plasma. The inhibition curves obtained when $25,50,100$ and $200 \mu \mathrm{l}$ plasma were assayed proved to be parallel to the standard curve. When various dilutions of exogenous testosterone were added to $100 \mu \mathrm{l}$ samples of musk shrew plasma, the exogenous testosterone was measured accurately. All experimental samples $(n=158)$ were run in 5 assays. Samples from each experiment were run within the same assay. Inter-assay and intra-assay variation averaged 16.6 and $4.8 \%$ respectively. The limit of sensitivity for this assay is $30 \mathrm{pg} / \mathrm{ml}$. Recovery of tritiated hormone measured after extraction averaged $84.9 \%$. Hormone values were not corrected for recovery.

Experiment 1. At weaning, males were randomly assigned to one of three housing conditions: males were raised alone in a small cage $(28 \times 17 \times 12 \mathrm{~cm}, \mathrm{~N}=10)$ or were housed with an adult female $(\mathrm{N}=9)$ or male (older than 6 months of age, $\mathrm{N}=11)$ in a large cage $(44 \times 24 \times 14 \mathrm{~cm})$. Pairs of animals housed together were provided with a plastic nest box $(8 \times 8 \times 6 \mathrm{~cm})$. The 30 males were maintained under these conditions for 20 days. An additional 26 
males $(\mathrm{N}=8-9$ per group) were used in the second run of this experiment which extended the cohabitation period for an additional 20 days.

Experiment 2. Weanling males were assigned to one of three housing conditions based on body weight. At the time of weaning, males were placed in groups in a manner that ensured equivalent initial average body weights per group. Males were maintained in a small cage alone $(N=10)$ or in a large cage with an adult female $(N=12$, as in Exp. 1). To examine the role of unrestricted physical contact with a female on male development a third group of males $(\mathrm{N}=12)$ was reared in 'split' cages with a single hardwire cloth screen separating them from their adult female cagemate. The split cages measured $38 \times 18 \times 11 \mathrm{~cm}$, and so each individual lived in an area half of that size $(19 \times 18 \times 11 \mathrm{~cm})$. The 34 males were housed under these conditions for 20 days. In the second half of the study an additional $31(\mathrm{~N}=10-11$ per group) males were housed for 40 days.

Experiment 3. Weanling males were assigned to one of three groups based on body weight. All males were individually housed in small cages. To evaluate the role of chemosignals on the development of young males, contact between young and adult animals was limited to exposure to chemical cues alone. Bedding in the males' cages was either clean, or soiled by an adult male or an adult female. Every 5 days young males were placed in a new cage that contained the same bedding type. In the groups receiving bedding from adult individuals, the same adult animal served as a donor for the same experimental male throughout the duration of the study. Thus, once every 5 days the donor adult animal received a clean cage and its soiled cage was allocated to its experimental male. This was done to ensure exposure to a variety of potential chemosignals. For example, by providing the young male with the entire cage the donor animals' urine, faeces and other scent marking odours would be available. In this study, 29 males $(\mathrm{N}=$ 9-10 per group) were maintained for 20 days and $29(\mathrm{~N}=9-10$ per group) were included in the longer experiment which ended after 40 days of treatment.

Males in the second part of this experiment were tested for sexual behaviour starting 4 days before the end of the experiment (at 56 days of age). Behavioural tests were conducted between 08:00 and 12:00 $\mathrm{h}$ in clean testing cages $(44 \times 23 \times 14 \mathrm{~cm})$. All animals were tested for sexual behaviour with stimulus females housed under normal colony conditions. Females were adults, tested $24-48$ h post partum, when receptivity is maximal (Rissman, 1987). Each musk shrew was given a maximum of two, 1-h behaviour tests separated by $48 \mathrm{~h}$. Males were tested a second time only if during their initial test they failed to exhibit a complete sequence of sexual behaviour culminating in ejaculation. Males were killed 2 days after their last behaviour test.

Experiment 4. To examine further the contribution of physical and visual contact with a female on the growth and reproductive development of the young male, weaning males were assigned (based on weight) to one of three housing conditions for a 40-day treatment period. Males were housed in the split cages used in Exp. 2 (dimensions: $38 \times 18 \times 11 \mathrm{~cm})$. In one condition males were housed alone in one half of the cage with a wire barrier separating them from the other side $(\mathrm{N}=10)$. In another group males were housed in an identical condition, but, a female was housed on the other side of the wire barrier $(N=9)$. In the final group males and females were housed on opposite sides of the split cage with a solid opaque barrier dividing the cage and thus prohibiting visual contact $(\mathrm{N}=9)$. In this experiment male body weights were recorded once every 5 days.

Analysis of data. The weights of reproductive accessory tissues were analysed using one-way analysis of covariance with body weight as the covariate. This procedure eliminates any influences of body weight on the analysis. To determine main effects of treatment on sperm numbers, androgen concentrations and sexual behaviours, one-way analyses of variance were applied. Growth data were analysed using a repeated measures ANOVA. Comparisons of group means were made with Student-Newman-Keuls multiple-range tests. Organ weight data presented graphically are taken from summaries of raw weights. The alpha level was set at $P<0.05$.

\section{Results}

\section{Experiment 1}

Males that cohabited with a female had significantly heavier reproductive organs and body growth than did males living alone or with adult males. After only 20 days of cohabitation, a significant effect of housing condition was seen on all measures recorded, except that sperm numbers did not differ between the groups. After 40 days of cohabitation all the same patterns were evident, except that testis weight and sperm counts were unaffected by housing (Table 1).

Males living with adult females for 20 days had heavier ampulla, flank pads, seminal vesicle/ prostate complex and testes than did males living alone or with an adult male $(P<0.05$ for each comparison). After 40 days of cohabitation this same pattern was seen for ampulla, flank pad, and seminal vesicle/prostate complex; males living with females had heavier organ weights than did males living with another male or alone ( $P<0.05$ for each comparison; Fig. 1). 
Table 1. Analysis (F values, and $P$ values in parentheses) of main effects of cohabitation with an adult on various reproductive parameters in young male musk shrews (Exp. 1)

\begin{tabular}{|c|c|c|}
\hline & \multicolumn{2}{|c|}{ Treatment days } \\
\hline & 20 & 40 \\
\hline $\begin{array}{l}\text { Seminal vesicle/prostate } \\
\text { complex wt }\end{array}$ & $16 \cdot 70(0 \cdot 0004)$ & $15.75(0.0007)$ \\
\hline Ampulla wt & $6.57(0.0168)$ & $5.07(0.035)$ \\
\hline Flank pad wt & $18 \cdot 26(0.0002)$ & $9.75(0.005)$ \\
\hline Testis wt & $5.52(0.027)$ & $0.34(\mathrm{NS})$ \\
\hline Sperm number & $0.50(\mathrm{NS})$ & $0.78(\mathrm{NS})$ \\
\hline Body wt & $16.67(0.0001)$ & $5.43(0.012)$ \\
\hline
\end{tabular}

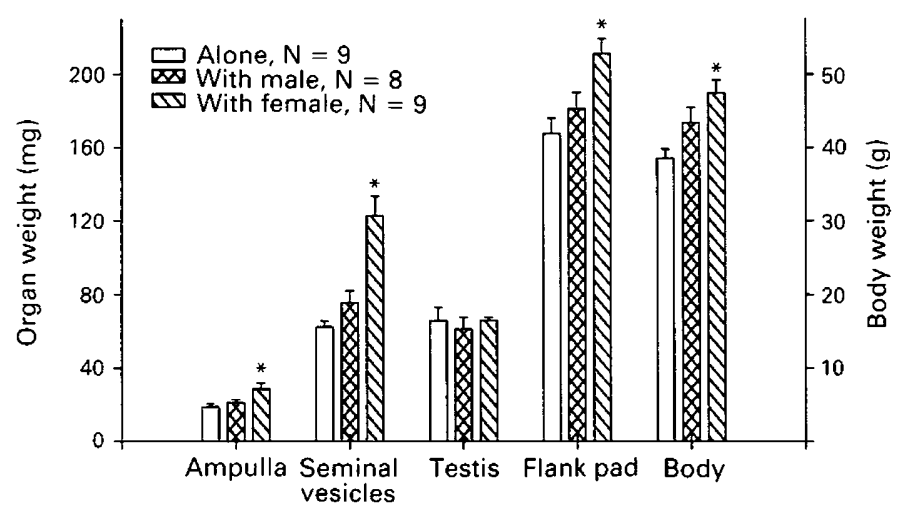

Fig. 1. Mean ( \pm s.e.m.) weights of reproductive organs in male musk shrews housed from weaning (20 days of age) for 40 days alone, with an adult male or an adult female (Exp. 1).

*Significantly $(P<0.05$ at least $)$ different from controls.

An analysis of the body growth data for animals receiving 40 days of treatment revealed significant effects of age $(\mathrm{F}(4,92)=314 \cdot 38, P<0.00001)$ and living condition $(\mathrm{F}(2,92)=5.43, P<0.02)$ as well as an interaction between these two variables $(\mathrm{F}(8,92)=8 \cdot 16, P<0.00001)$. As early as 10 days after weaning males housed with females were heavier than males housed alone, and they remained larger at every time point thereafter $(P<0.01)$.

\section{Experiment 2}

Males that cohabited with a female or across a wire barrier from a female had significantly heavier reproductive organs and body weights than did males living alone. After only 20 days of exposure to a female, a significant effect of housing condition was seen on ampulla, flank pad, seminal vesicle/prostate complex and body weights $(P<0 \cdot 006)$. Sperm counts and plasma androgen concentrations did not differ between the groups. By 40 days of treatment these same effects were noted. In addition, at this time point testicular weights and androgen concentrations differed between the groups (Table 2).

Males living with adult females for 20 days had heavier testes, seminal vesicle/prostate complexes and ampullae than did males living across a wire barrier from a female or alone $(P<0.05$ at least for each comparison). Flank pads were equivalent in weight in the two groups of males exposed to females and heavier than those measured in males living alone $(P<0.05)$. After 40 days 
Table 2. Analysis (F values, and $P$ values in parentheses) of main effects of direct versus indirect with an adult female on various reproductive parameters in young male musk shrews

(Exp. 2)

\begin{tabular}{|c|c|c|}
\hline & \multicolumn{2}{|c|}{ Treatment days } \\
\hline & 20 & 40 \\
\hline $\begin{array}{l}\text { Seminal vesicle/prostate } \\
\text { complex wt }\end{array}$ & $19 \cdot 78(0.0001)$ & $33.27(0.0001)$ \\
\hline Ampulla wt & $27.69(0.0001)$ & $6.73(0.015)$ \\
\hline Flank pad wt & $26 \cdot 23(0 \cdot 0001)$ & $25.50(0.0001)$ \\
\hline Testis wt & 0.47 (NS) & $24.85(0.0001)$ \\
\hline Sperm number & $0.86(\mathrm{NS})$ & $0.07(\mathrm{NS})$ \\
\hline Body wt & $7.45(0.0023)$ & $9.94(0.0005)$ \\
\hline Androgen conc. $(\mathrm{ng} / \mathrm{ml})$ & $0.80(\mathrm{NS})$ & $4.40(0.0217)$ \\
\hline
\end{tabular}

of treatment males living across a barrier from a female or cohabiting with a female had heavier seminal vesicle/prostate complexes, ampulla and flank pads than did males living alone $(P<0 \cdot 05)$. Plasma androgen concentrations were higher in males living across a barrier from females than in males living alone $(P<0.01$; Fig. 2).

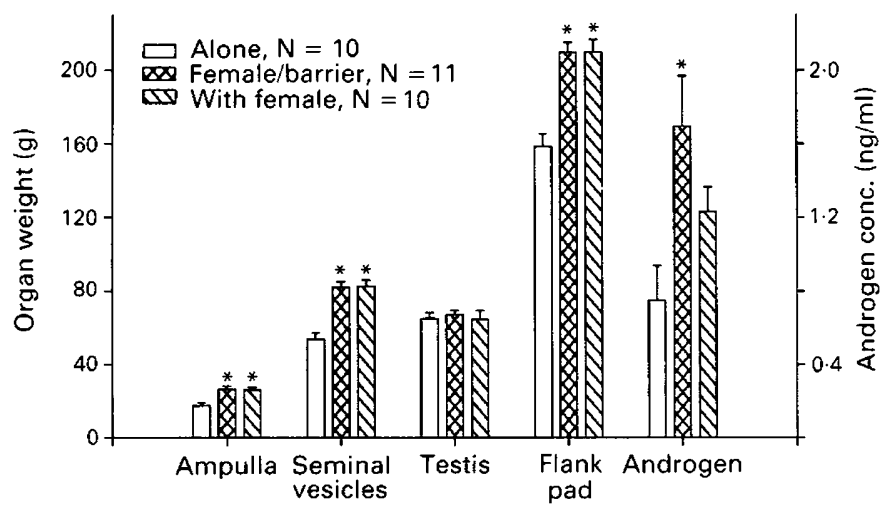

Fig. 2. Mean ( \pm s.e.m.) weights of four reproductive organs and plasma androgen concentrations in male musk shrews housed from weaning ( 20 days of age) for 40 days alone, with an adult female housed across a screen barrier, or living directly with an adult female (Exp. 2). *Significantly $(P<0.05$ at least $)$ different from controls.

An analysis of the body growth data for animals studied for 40 days revealed significant effects of age $(\mathrm{F}(4,112)=285.05, P<0.00001)$, and living condition $(\mathrm{F}(2,112)=9.94, P<0.0005)$ as well as an interaction between these two variables $(\mathrm{F}(8,112)=10 \cdot 12, P<0 \cdot 00001)$. As in Exp. 1 , as early as 10 days after weaning, males housed with or separated from a female were heavier than males housed alone, and they remained larger than solitary males at every time point thereafter $(P<0.01$; Fig. 3).

\section{Experiment 3}

Housing males in soiled bedding taken from adult conspecifics had some significant effects on reproductive development after 20 days of treatment. However, by 40 days of treatment most of these effects were not found. Housing males for 20 days in clean, male-soiled or female-soiled 


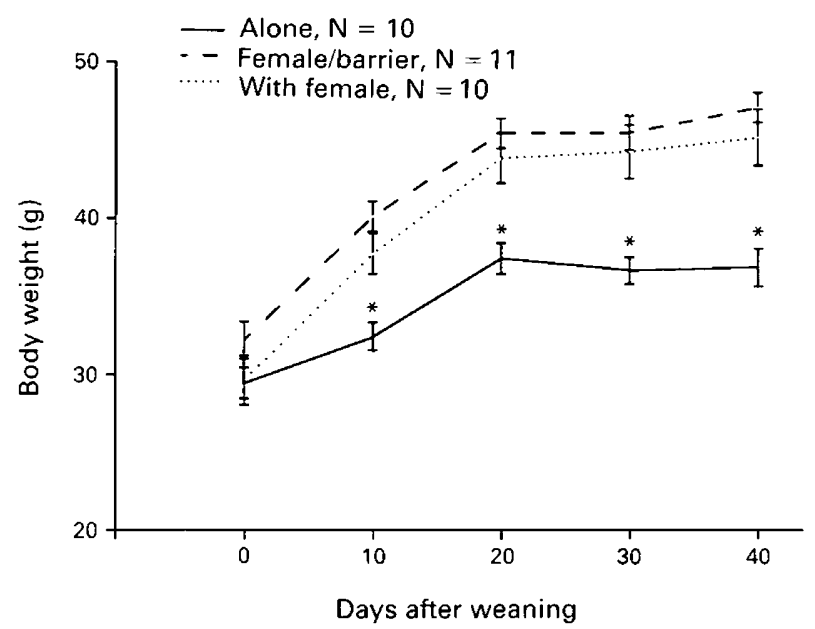

Fig. 3. Mean ( \pm s.e.m.) body weights of males in Exp. 2. *Significantly $(P<0.05)$ different from values for the other two groups.

bedding affected seminal vesicles/prostate, flank pad and testis weights as well as androgen concentrations in plasma (Table 3). By 40 days of treatment only seminal vesicle/prostate weights were affected (Fig. 4).

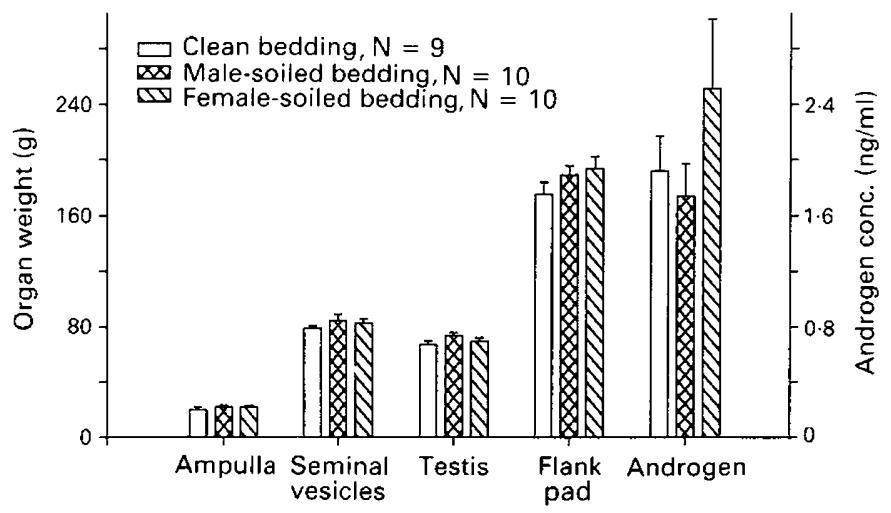

Fig. 4. Mean ( \pm s.e.m.) body and reproductive organ weights in male musk shrews housed from weaning ( 20 days of age) for 40 days alone in clean bedding, or soiled bedding taken from an adult male or female (Exp. 3).

Pairwise comparisons of the means revealed only one specific difference between groups of males after 20 or 40 days of treatment. After 20 days of treatment males housed in soiled bedding taken from adult males had higher plasma androgen values than did males reared in clean bedding $(P<0.05)$.

Body weights varied with age $(\mathrm{F}(4,104)=273.49, P<0.00001)$, but not with living condition $(F(2,104)=0 \cdot 76)$, nor was an interaction between these factors noted $(F(8,104)=0 \cdot 78)$. In addition, the three parameters of sexual behaviour measured, latency to mounting, number of mounts before ejaculation and latency to ejaculation were unaffected by housing condition after 40 days of treatment (Table 3 ). 
Table 3. Analysis ( $\mathrm{F}$ values, and $P$ values in parentheses) of main effects of soiled bedding from adults on various reproductive parameters in young male musk shrews (Exp. 3)

\begin{tabular}{|c|c|c|}
\hline & \multicolumn{2}{|c|}{ Treatment days } \\
\hline & 20 & 40 \\
\hline $\begin{array}{l}\text { Seminal vesicle/prostate } \\
\text { complex wt }\end{array}$ & $9.84(0.004)$ & $12.35(0.002)$ \\
\hline Ampulla wt & 1.83 (NS) & $1 \cdot 19(\mathrm{NS})$ \\
\hline Flank pad wt & $4.22(0.05)$ & $2 \cdot 11$ (NS) \\
\hline Testis wt & $9.61(0.005)$ & $3 \cdot 34$ (NS) \\
\hline Sperm number & $1 \cdot 30$ (NS) & $1 \cdot 13$ (NS) \\
\hline Body wt & $0.16(\mathrm{NS})$ & 0.76 (NS) \\
\hline Androgen conc. $(\mathrm{ng} / \mathrm{ml})$ & $3.75(0.038)$ & $1.06(\mathrm{NS})$ \\
\hline Latency to mounting & - & 0.78 (NS) \\
\hline No. of mounts & - & $2 \cdot 21$ (NS) \\
\hline Latency to ejaculation & - & 1.24 (NS) \\
\hline
\end{tabular}

\section{Experiment 4}

There were no main effects of treatment on any measures except body weight $(F(2,25)=5 \cdot 82$, $P<0.01)$ in this study. Pairwise comparisons revealed that males housed across a wire barrier from females had heavier seminal vesicle/prostate complexes than did males housed alone $(P<0.05)$. Also, males housed across a wire mesh from a female had heavier flank pads than did males housed across an opaque barrier from a female, or alone $(P<0.05$; Fig. 5).

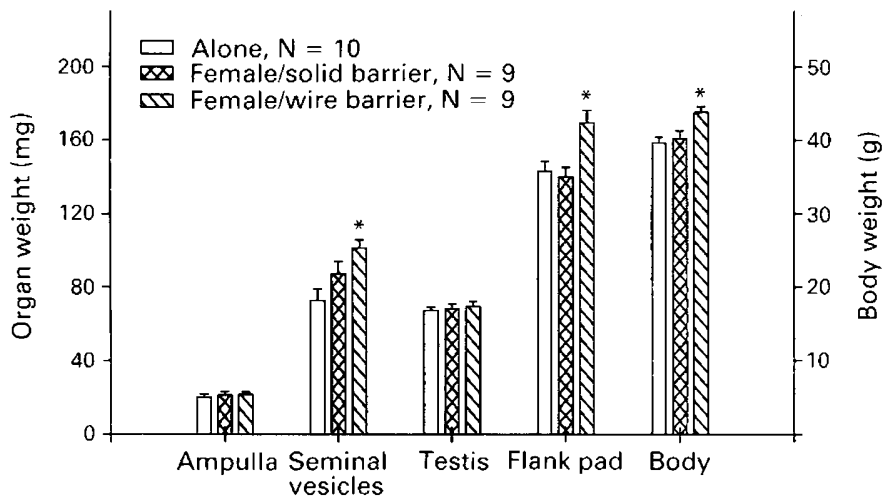

Fig. 5. Mean ( $t$ s.e.m.) weights of four reproductive organs and body weights in male musk shrews housed from weaning ( 20 days of age) for 40 days alone in a split cage, or with a female in the other half of the cage. Pairs were separated by a solid, opaque barrier, or a wire barrier (Exp. 4). *Significantly different from controls $(P<0.05)$. For flank pad and body weights * values also differ from those in animals reared in the solid barrier condition.

Body weights did vary with age $(\mathrm{F}(8,200)=255 \cdot 86, P<0 \cdot 00001)$ and housing condition $(\mathrm{F}(2,200)=6.89, P<0.004)$. In addition there was a significant interaction between these two factors $(\mathrm{F}(16,200)=3.31, P<0.00001)$. By 30 days of age the animals in the three different treatment groups showed significant variation in body weights; this difference persisted for the duration of the experiment. 


\section{Discussion}

The results clearly show that reproductive function in the male musk shrew can be influenced by the individual male's social environment. Cohabitation with an adult female, but not an adult male, resulted in both an acceleration of growth of reproductive tissues as well as the attainment of heavier adult body weights. After only 20 days of cohabitation, males living with females had significantly heavier reproductive organs than did males living with an adult male or alone. These differences were also noted in males allowed to cohabit with another shrew, or live alone, for a total of 40 days. Body growth was similarly affected by the male's social environment. Males living with females gained body weight rapidly and continued to maintain their weights at a heavier level than did controls for the duration of the study.

The results of the second experiment replicated the effects noted in the first study and also shed some light on the nature of the female-related social cue. Experiment 2 demonstrated that young males reared across a wire barrier from an adult female also have heavier reproductive organs and body weights than males housed alone. However, these effects took longer to manifest than in Exp. 1 since they were not complete by 20 days of treatment. Only after 40 days of treatment were weights of reproductive tissues in males living across a wire barrier equivalent to those measured in males cohabiting with females. The results suggest that direct, unlimited physical contact with a female is not essential for the female to produce these striking effects on male maturation. The third experiment tested the hypothesis that exposure to soiled bedding taken from an adult female would accelerate maturation. After 20 days of treatment some acceleration was noted. However, pairwise comparisons only yield a difference in plasma androgen concentrations between males raised in male-soiled versus clean bedding. These data suggest, but do not prove, that the social signal is probably not exclusively pheromonal, but that visual, auditory, and/or tactile cues are also involved. Although the data from Exp. 4 are not conclusive they lend support to the hypothesis that visual contact between the pair is important. This is particularly true of the effect of the female on male body growth since growth curves of males reared behind a solid barrier from a female are identical to those of solitary males. Alternatively, it is possible that pheromonal cues are involved, or that these cues are normally of secondary importance and act perhaps synergistically with other cues. In addition, auditory signals may be important and could be compromised when visual cues are not available.

Considering the opportunistic characteristics of reproduction in the musk shrew (Peterson, 1956), it is not surprising that positive social signals (the presence of a non-pregnant adult female) caused accelerated growth and maturation in males. On the other hand, potentially inhibitory signals (the presence of an adult male) did not influence maturational rate. In addition, the limited effects of social condition reflect the opportunistic nature of sexual development in this species, in that sperm production was not affected by social condition. Puberty is a multi-dimensional event and one important aspect not examined here is male fertility. One critical test of the effects of social cues on maturation currently under investigation includes an examination of the ability of males reared in different social environments to impregnate females.

The present results can be compared to similar studies with temperate-zone rodents. In the male mouse (Fox, 1968; Vandenbergh, 1971) testes and seminal vesicle weights were heavier in young animals living with females than in males living with adult males. In the male deer mouse (Bediz \& Whitsett, 1979), cohabitation with an adult male influenced testicular and seminal vesicle growth in a negative direction. Exposure to urine taken from an adult male (Lawton \& Whitsett, 1979) produced weaker effects as manifested by a small difference in body and seminal vesicle weights. Finally, in several vole species, males mature more slowly (as assessed by sexual behaviour, androgen concentrations and seminal vesicle weights) when given prolonged exposure to their mothers or chemical cues from the natal nest (Rissman et al., 1984; Carter \& Getz, 1985). Taken together these data suggest that social cues have effects on male musk shrew similar to those seen in rodent species. However, in addition, social condition has pronounced effects on body weight and growth 
in the musk shrew. Unlike the data collected for rodents (using methods similar to ours, for example Rissman et al., 1984), the results of Exp. 3 suggest that pheromonal cues play a less important role in the effect of the female on male growth and sexual development in musk shrews than they do in rodents. As demonstrated in female mice (Bronson \& Maruniak, 1975) perhaps a number of social signals (such as visual, auditory, tactile and/or olfactory cues) work independently and/or synergistically in this animal.

Perhaps the most intriguing aspect of these results is the body weight responses of young males given exposure to adult females. Merely living across a wire screen from a female caused a pronounced and prolonged increase in body weight. Even after 40 days of these living conditions, males exposed to females (in Exps 2 and 4) were on average $8 \mathrm{~g}$ heavier than males housed alone. This represents about a $15 \%$ difference in weight. Since the reproductive responses are seen, whether or not organ weights are adjusted for body weight differences between individuals, these two responses may be two separate but perhaps interrelated effects of female exposure. Several hypotheses could potentially explain the differences in body weight between solitary and femaleexposed males. One simple explanation is that contact with a female stimulates feeding and these males have increased food intake. Recent data (Wayne \& Rissman, 1990) confirm that this is the case. Exactly how this increased caloric intake is triggered, by which aspects of the male/female social interaction, and how these extra calories are converted into gains in reproductive development are of interest. Whatever the mechanism it is clear that increased body mass could confer reproductive advantages to these males. Little is known about the natural history of the musk shrew. However, the field data on population densities (Peterson, 1956; Morita, 1964) and the large dimorphism between the sexes in body size (males are twice the body weight of females) suggest that these animals are primarily polygamous in their mating system. In this case, greater body mass could confer an advantage in territory acquisition for males and in success in direct competition among males for access to females.

We thank Ms Sue Harlow for technical assistance and Dr Eric Turkheimer for advice and help with the statistical analyses. This work was supported by NSF grant BNS 8706770 and NIH grant 5T32-MH-18411.

\section{References}

Barbahenn, K.R. (1962) Recent invasions of micronesia by small mammals. Micronesia 10, 41-50.

Bediz, G.M. \& Whitsett, J.M. (1979) Social inhibition of sexual maturation in male prairie deer mice. J. comp. Physiol. Psychol. 93, 493-500.

Bronson, F.H. (1979) The reproductive ecology of the house mouse. Quart. Rev. Biol. 54, 265-299.

Bronson, F.H. (1985) Mammalian reproduction: an ecological perspective. Biol. Reprod. 32, 1-26.

Bronson, F.H. \& Maruniak, J.A. (1975) Male-induced puberty in female mice: evidence for a synergistic action of social cues. Biol. Reprod. 13, 94-98.

Bronson, F.H. \& Rissman, E.F. (1986) The biology of puberty. Biol. Rev. 61, 157-195.

Carter, C.S. \& Getz, L.L. (1985) Social and hormonal determinants of reproductive patterns in the prairie vole. In Comparative Neurobiology, pp. 18-36. Eds R. Gilles \& J. Balthazart. Springer-Verlag, Berlin.

Fox, K.A. (1968) Effects of prepubertal habitation conditions on the reproductive physiology of the male house mouse. J. Reprod. Fert. 17, 75-85.

Gay, V.L. \& Kerlan, J.T. (1978) Serum LH and FSH following passive immunization against circulating testosterone in the intact male rat and in orchidectomized rats bearing subcutaneous silastic implants of testosterone. Archs Androl. 1, 239-240.

Harrison, J.L. (1955) Data on the reproduction of some Malayan mammals. Proc. zool. Soc. Lond. 125, 445460 .

Kirton, K.T., Desjardins, C. \& Hafs, H.D. (1967) Distribution of sperm in male rabbits after various ejaculation frequencies. Anat. Rec. 158, 287-292.

Lawton, A.D. \& Whitsett, J.M. (1979) Inhibition of sexual maturation by a urinary pheromone in male prairie deer mice. Horm. Behav. 13, 128-138.

Louch, C.D., Ghosh, A.K. \& Bikash, C.P. (1966) Seasonal changes in weight and reproductive activity of Suncus murinus in West Bengal, India. J. Mammal. 47, 73-78.

Morita, S. (1964) Reproduction of the Riukiu musk shrew, Suncus murinus riukiuanus. Sci. Bull. Fac, Lib. Arts and Educ., Nagasaki Univ. 15, 17-40.

Peterson, G.D. (1956) Suncus murinus, a recent introduction to Guam. J. Mammal. 37, 278-279.

Petter-Rousseaux, A. (1970) Observations sur l'influence de la photoperiode sur l'activite sexuelle chez 
Microcebus murinus en captivite. Annls Biol. anim. Biochim. Biophys. 10, 203-288.

Rissman, E.F. (1987) Social variables influence female sexual behavior in the musk shrew (Suncus murinus). J. comp. Psychol. 101, 3-6.

Rissman, E.F., Sheffield, S.D., Kretzmann, M.B., Fortune, J.E. \& Johnston, R.E. (1984) Chemical cues from families delay puberty in male California voles. Biol. Reprod. 31, 324-331.

Rissman, E.F., Nelson, R.J., Blank, J.L. \& Bronson, F.H. (1987) Reproductive response of a tropical mammal, the musk shrew (Suncus murinus), to photoperiod. $J$. Reprod. Fert. 81, 563-566.

Sadleir, R.M.F.S. (1969) The Ecology of Reproduction in Wild and Domestic Mammals. Methuen and Co., London.

Schilling, A. \& Perret, M. (1987) Chemical signals and reproductive capacity in a male prosimian primate (Microcebus murinus). Chem. Sens. 12, 143-158.

Vandenbergh, J.G. (1971) The influence of the social environment on sexual maturation in male mice. $J$. Reprod. Fert. 24, 383-390.
Vandenbergh, J.G. (1983) Pheromonal regulation of puberty. In Pheromones and Reproduction in Mammals, pp. 95-112. Ed. J. G. Vandenbergh. Academic Press, New York.

Van Horn, R.N. (1975) Primitive breeding season: photoperiodic regulation in captive Lemur catta. Folia Primatol. 24, 203-220.

Wayne, N.L. \& Rissman, E.F. (1990) Environmental regulation of reproduction in an opportunistic breeder: the musk shrew (Insectivora: Suncus murinus). In Progress in Comparative Endocrinology, pp. 440-473. Eds A. Epple, C. G. Scanes \& M. H. Stetson. Wiley-Liss, New York.

Zucker, I., Johnston, P.G. \& Frost, D. (1980) Comparative, physiological and biochronometric analysis of rodent seasonal reproductive cycles. Prog. Reprod. Biol. 5, 102-133.

Received 5 December 1989 